\title{
Natural product-derived quaternary ammonium compounds with potent antimicrobial activity
}

\author{
Maureen D Joyce ${ }^{1}$, Megan C Jennings ${ }^{2}$, Celina N Santiago ${ }^{1}$, Madison H Fletcher ${ }^{2}$, William M Wuest ${ }^{2}$ and \\ Kevin PC Minbiole ${ }^{1}$
}

The Journal of Antibiotics (2016) 69, 344-347; doi:10.1038/ja.2015.107; published online 18 November 2015

Dedicated to Professor Amos B. Smith, III, in celebration of his seminal contributions to basic science and human health.

Quaternary ammonium compounds (QACs) bearing long alkyl chains are classical examples of amphiphiles, displaying a variety of interesting physical properties, such as the capacity for micelle formation and gelation. ${ }^{1}$ QACs also enjoy extensive precedent and applications in bacterial cell membrane disruption, leading to their widespread use as antiseptics. ${ }^{2}$ Both synthetic QACs and peptide-based amphiphiles (notably, antimicrobial peptides or $\mathrm{AMPs}^{3}$ ) are prevalent. However, aside from modified peptides, there are relatively few QACs in scaffolds of natural products.

Amongst the examples of natural products with permanent cationic charges based at nitrogen are a series of tetrahydroisoquinolinium structures isolated from the Chinese vine Gnetum montanum, including magnocurarine, cyclized derivatives thereof, and the latifolians, ${ }^{4}$ as illustrated in Figure 1a. Latifolian A demonstrated modest antimicrobial activity, with a MIC of $35 \mu \mathrm{M}$ against Pseudomonas aeruginosa. ${ }^{5}$ However, it only demonstrated 55\% inhibition of methicillin-resistant Staphyloccocus aureus (MRSA) at $350 \mu \mathrm{M}$ while magnocuraine and its tetracyclic derivatives showed no effectiveness at this concentration, which perhaps correlates to the lack of an alkyl chain.

Related isoquinolinium structures bearing additional aromatic rings include chelerythrine, sanguinarine and berberine. Berberine, also identified from a Chinese herb, has shown micromolar activity against P. aeruginosa. ${ }^{6}$ Other quinolinium natural products with a quaternary ammonium center include tabouensinium chloride ${ }^{7}$ and the quinocitrines. ${ }^{8}$ Finally, ageloxime $\mathrm{D}^{9}$ and dehydroevodiamine ${ }^{10}$ diversify this structural class and present a positive charge delocalized over two nitrogens. In sum, a trend emerges; half of the illustrated natural products that possess quaternized nitrogen atoms simply represent $\mathrm{N}$-methylated alkaloids, and overall structural variety is modest.

Inspired by these natural precedents, we set out to address a question: could natural products lacking a quaternary ammonium group be converted into QACs, and thus gain antimicrobial activity? We were determined to confer amphiphilic properties to natural products that are not, in their own right, antibacterial agents. Further, we aimed to generate analogous series of structures that could bear one or two cationic residues, as multicationic QACs (multiQACs) have been recently shown to exhibit strong antibacterial activity, and importantly, be able to evade the QAC resistance traits observed due to efflux pumps. The function of bisQACs in particular still requires investigation, as aromatic derivatives seem to show more susceptibility to bacterial resistance than their alkyl counterparts. ${ }^{11}$

Two natural products that presented themselves as ideal core structures for this investigation were quinine and nicotine (Figure 1b). Each presents a pyridine nitrogen, as well as a separate tertiary amine with only modest steric hindrance. Each compound is naturally abundant, therefore, making it inexpensive, and presents no significant reported antibacterial property as the unmodified natural product. Furthermore, although each has precedent to react as chiral bases ${ }^{12}$ and nucleophiles, neither has been systematically investigated regarding their alkylation to form antimicrobial amphiphiles. ${ }^{13,14}$

Interestingly, these two natural products present opposite trends in their reported alkylation chemistry; nicotine is preferably alkylated at its pyridine nitrogen, ${ }^{15}$ and quinine is precedented to react at its tertiary aliphatic amine (Figure $1 \mathrm{~b}) .{ }^{16}$ For both compounds, however, little is known about the amphiphilic properties of long-chain alkylated derivatives, though some nicotine-based amphiphiles have been investigated for their affects on the central nervous system ${ }^{17}$ and applications as ionic liquids; ${ }^{18}$ quinine derivatives have served as phase-transfer catalysts ${ }^{19}$ and substrates for phosphorylation. ${ }^{20} \mathrm{We}$ thus set out to prepare a series of mono- and bis-alkylated derivatives of quinine and nicotine for the purpose of evaluating their antimicrobial potential.

To this end, we first explored the alkylation of quinine, which proceeded under high-concentration conditions $\left(\sim 1 \mathrm{M}, \mathrm{CH}_{3} \mathrm{CN}\right)$ using a variety of alkyl bromide electrophiles (Figure 2a). Yields were uniformly high, and led to a simple production of the monocationic compounds abbreviated as Q-n,0 (Figure 2c). Subsequent alkylation proved to be limited in scope; we found that a second alkylation with a

${ }^{1}$ Department of Chemistry, Villanova University, Villanova, PA, USA and ${ }^{2}$ Department of Chemistry, Temple University, Philadelphia, PA, USA

Correspondence: Professor WM Wuest, Department of Chemistry, Temple University, 1801N Broad St, Villanova, PA 19085, USA.

E-mail: wwuest@temple.edu

or Professor KPC Minbiole, Department of Chemistry, Villanova University, Chemistry, 800 E Lancaster Ave, Villanova, PA 19085, USA.

E-mail: kevin.minbiole@villanova.edu

Received 13 August 2015; revised 10 September 2015; accepted 24 September 2015; published online 18 November 2015 
a<smiles>COc1cc2c(cc1O)[C@H](Cc1ccc(O)cc1)C(C)(C)CC2</smiles>

magnocurarine<smiles></smiles>

$\mathrm{R}=\mathrm{CH}_{3}$ : chelerythrine

$\mathrm{R}=-\mathrm{CH}_{2}-$ : sanguinarine<smiles>COc1c2c([n+](C)c3ccccc13)OC(C)(C)C(C)(O)C2</smiles>

tabouensinium chloride<smiles>COc1cc2c3c(c1O)-c1cc(O)c(O)cc1C[C@H]3N(C)CC2</smiles>

1,9,10-trihydroxy-2methoxy-6-methyl aporphinium trifluoroacetate<smiles>COc1cc2c3c(cc4cc(O)c(O)cc4c3c1O)[N+](C)(C)CC2</smiles>

6a,7-didehydro-1,9,10-trihydroxy2-methoxy-6-methylaporphinium trifluoroacetate<smiles>C[C@H]1c2cc(O)c(O)cc2C[C@H]2c3cc(O)c(O)cc3C[C@@H]2c2cc(O)c(O)cc21</smiles><smiles></smiles>

berberine<smiles>C=C1CC[C@H]2[C@@H](C)CCC[C@]2(C)[C@H]1CC/C(C)=C/Cn1c[n+](C)c2nc[nH]/c(=N\O)c21</smiles><smiles></smiles>

quinocitrinines $A$ and $B$<smiles>CN1C2=C(CCN3C2=Nc2ccccc2C(=O)N3C)Nc2ccccc21</smiles>

dehydroevodiamine<smiles>[R]N1CC2CC1C(C=C)C[C@H]2[C@H](O)c1ccnc2ccc(OC)cc12</smiles><smiles>C=CC1CN2CCC1CN2[C@H](O)c1ccnc2ccc(OC)cc12</smiles>

(-)-quinine<smiles>CCN1CCC[C@H]1c1cccnc1</smiles><smiles>[2H][n+]1cccc([C@H]2CCCN2C)c1</smiles>

(-)-nicotine

Figure 1 Natural products and their derivatives. (a) Examples of quaternary ammonium natural products. (b) Quinine and nicotine, and alkylation thereof.

long-chained alkyl bromide or iodide was difficult to complete, resulting in a mixture of compounds. However, exposure to neat methyl iodide led to nearly quantitative alkylation overnight, affording the Q-n,1 series after simple evaporation. Characterization data and experimental details for all synthesized compounds are provided in the Supplementary Information.

Nicotine derivatives were alkylated in a highly analogous manner, again leading to alkylation in high yields (1 equiv $\mathrm{RBr}, \mathrm{CH}_{3} \mathrm{CN}, \Delta$, $\mathrm{o} / \mathrm{n}$ ), as illustrated in Figure $2 \mathrm{~b}$. As predicted by literature examples, we saw exclusive alkylation at the pyridine nitrogen. Subsequent alkylation, converting the $\mathrm{N}-\mathrm{n}, 0$ series to the $\mathrm{N}-\mathrm{n}, 1$ series, proceeded somewhat more slowly, completing in $48 \mathrm{~h}$ at high yield. Evaporation provided the final set of compounds abbreviated as N-n,1, setting the stage for biological investigation.

MIC values against Gram-positive Staphylococcus aureus (methicillin-susceptible Staphyloccocus aureus (MSSA) and two MRSA strainsUSA300-0114 and ATCC33591) and Enterococcus faecalis and Gramnegative Escherichia coli and $P$. aeruginosa were determined according to standard methods (Supplementary Information), and results appear in Figure 2c.

The amphiphiles derived from both quinine and nicotine displayed strong antibacterial activity against a number of Gram-positive and
Gram-negative strains. Control compounds, including the parent natural products as well as their bis-methylated derivatives (Q-1,1 and $\mathrm{N}-1,1)$ showed essentially no antimicrobial activity in our hands. Longer chain alkyl derivatives of these natural products showed clear correlations between alkyl chain length and antimicrobial activity. In the nicotine series, the strongest activity was observed for $\mathrm{N}-16,0$ and $\mathrm{N}-18,1$ for the mono- and bisQACs, respectively. Each showed low micromolar activity $(\leqslant 4 \mu \mathrm{M})$ for all bacteria except for $P$. aeruginosa. For the monocationic quinine derivatives, the strongest activity was observed for Q-14,0; however, longer chains proved optimal for the bisQACs (Q-16,1 and Q-18,1), and in fact provided two amphiphiles with single-digit micromolar activity against all bacteria tested. The modest inconsistencies in optimal chain length are somewhat unexpected, and may reflect an optimum balance between polar and nonpolar sections of the amphiphiles, as well as the markedly different core natural products.

We were surprised to observe roughly comparable activity when comparing the mono- and bis-cationic compounds for most of this data set. BisQACs did not prove uniformly more potent than the singly cationic analogs, and in many cases proved inferior to the analogous monoQACs (for example, $\mathrm{N}-12,0$ vs $\mathrm{N}-12,1$ ). When comparing activity against MSSA and MRSA (shaded entries in 


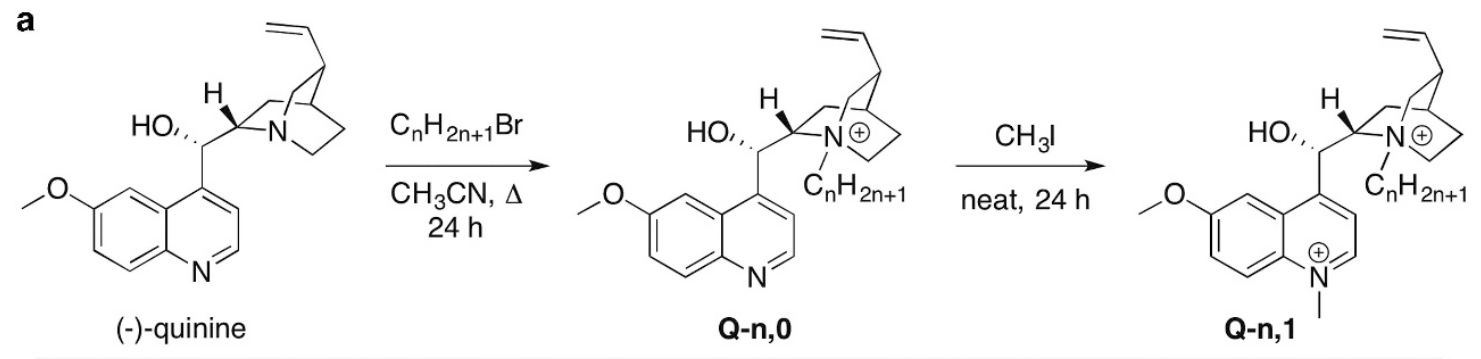

b<smiles>CN1CCC[C@H]1c1cccnc1</smiles>

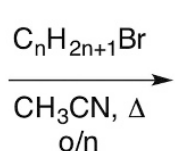

(-)-nicotine

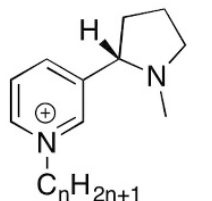

$\mathrm{N}-\mathrm{n}, \mathbf{0}$

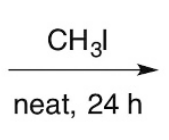<smiles>CCCCCCCC[n+]1cccc([C@@H]2CCC[N+]2(C)C)c1</smiles>

N-n,1

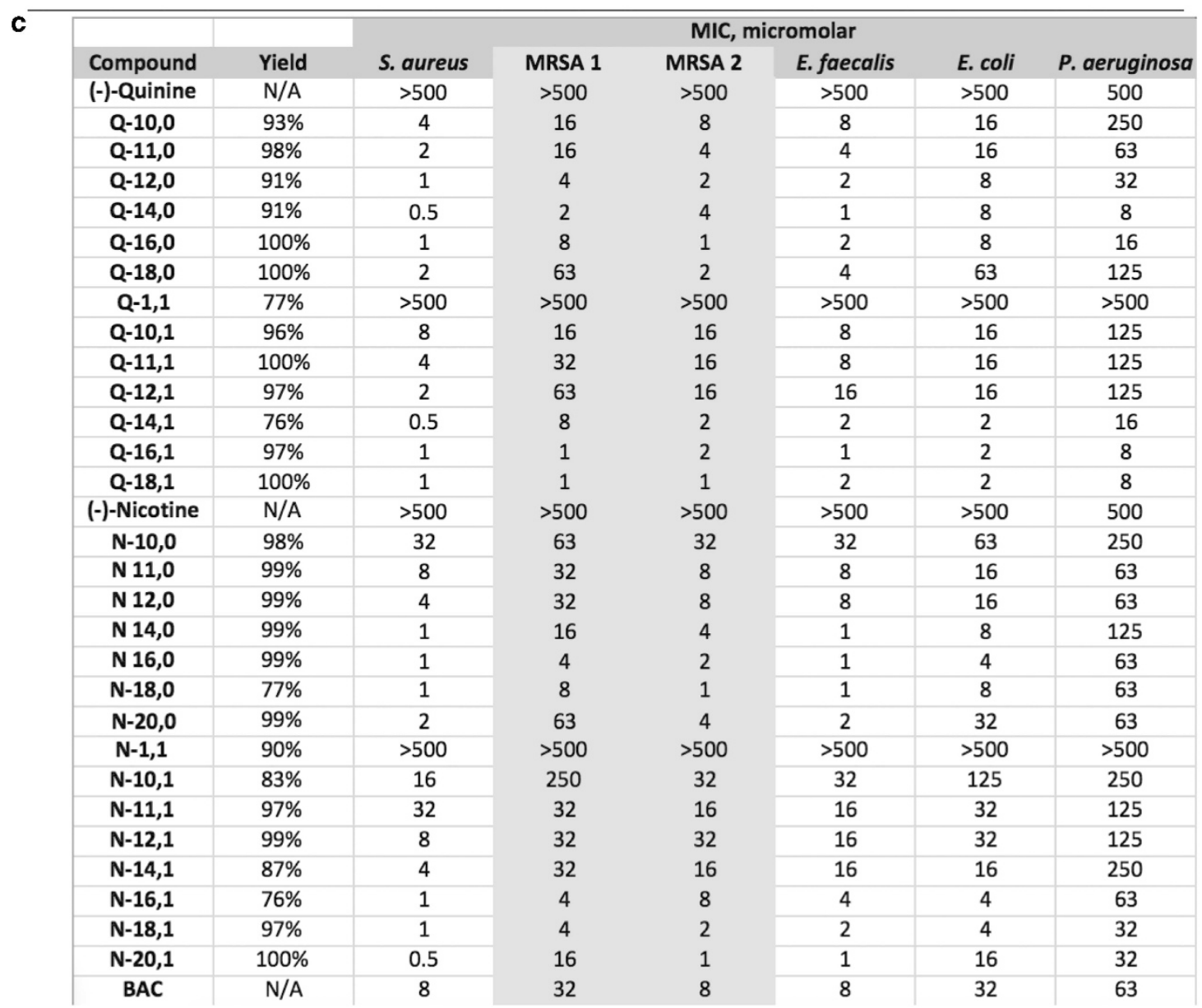

Figure 2 Synthesis of (a) quinine- and (b) nicotine-derived quaternary ammonium compounds, with (c) synthetic and biological data. Results from two MRSA strains are shaded. MRSA $1=$ USA300-0114; MRSA 2=ATCC33591; BAC, benzalkonium chloride.

Figure 2c), nearly every natural product-derived QAC showed significant levels of bacterial resistance, with up to a 32 -fold higher MIC for MRSA strains. In fact, in only two of the 28 compounds prepared did we observe comparable activity against MSSA and MRSA -only Q-16,1 and Q-18,1 were unaffected by QAC resistance. This stands in stark contrast to Q-18,0, which showed strong susceptibility to MRSA resistance, resulting in a 32-fold increase in MIC of MRSA as compared to MSSA. This largely supports previous observations that
MRSA resistance seems to be associated with monoQACs as well as bisQACs based on aromatic substrates, ${ }^{11}$ but it is possible that alkyl chain length should also be a consideration.

In summary, we have demonstrated that selected natural products can serve as the platform for amphiphile construction, and that such derivatization is capable of imparting significant levels of antibacterial activity. Further, we have corroborated the observation that monoQACs are susceptible to MRSA resistance, presumably through the 
effect of efflux pumps. ${ }^{20}$ Such observations were not as clear for bisQACs, wherein we observed MRSA resistance for the majority of compounds, yet two longer chained bisQACs derived from quinine showed no resistance at all to two MRSA strains. In light of the simplicity of synthesis, and potency of many of the compounds presented herein, we suggest natural product derivatization as a viable strategy for antiseptic discovery, and perhaps as an inspiration for future antibiotics.

\section{CONFLICT OF INTEREST}

The authors declare no conflict of interest.

\section{ACKNOWLEDGEMENTS}

This work was funded by a University City Science Center QED Proof of Concept Grant (Grant S1403 to WMW), as well as by Temple and Villanova Universities. MCJ acknowledges a National Science Foundation Pre-Doctoral Fellowship (DGE1144462). The authors thank CW Ross (Temple Mass Spectrometry Facility) for obtaining MS data.

1 Steichen, D. S. in Handbook of Applied Surface and Colloid Chemistry (ed. Holmberg K.) 310-347 (John Wiley \& Sons, Ltd., New York, 2002).

2 Walker, E. B. \& Paulson, D. Quaternary Ammonium Compounds (Marcel Dekker, New York, 2002).

3 Guani-Guerra, E., Santos-Mendoza, T., Lugo-Reyes, S. O. \& Teran, L. M. Antimicrobial peptides: general overview and clinical implications in human health and disease. Clin. Immun. 135, 1-11 (2010).

4 Rochfort, S. J. et al. Latifolians A and B, novel JNK3 kinase inhibitors from the papua new guinean plant Gnetum latifolium. J. Nat. Prod. 68, 1080-1082 (2005).

5 Martin, F. et al. Alkaloids from the Chinese Vine Gnetum montanum. J. Nat. Prod. 74, 2425-2430 (2011).
6 Čerňáková, M. \& Koštálová, D. Antimicrobial activity of berberine-a constituent of Mahonia aquifolium. Folia Microbiol. 47, 375-378 (2002).

7 Wabo, H. K. et al. Tabouensinium chloride, a novel quaternary pyranoquinoline alkaloid from Araliopsis tabouensis. Nat. Prod. Res. 19, 591-595 (2005).

8 Kozlovsky, A. G., Zhelifonova, V. P. \& Antipova, T. V. The fungus Penicillium citrinum, isolated from permafrost sediments, as a producer of ergot alkloids and new quinoline alkalods quinocitrinines. Appl. Biochem. Microbiol. 41, 499-502 (2005).

9 Hertiani, T. et al. From anti-biofouling to biofilm inhibition: new cytotoxic secondary metabolites from two Indonesian Agelas sponges. Bioorg. Med. Chem. 18, 1297-1311 (2010).

10 Park, C. H. et al. Novel anticholinesterase and antiamnesic activities of dehydroevodiamine, a constituent of Evodia rutaecarpa. Planta Med. 62, 405-409 (1996).

11 Jennings, M. C., Minbiole, K. P. C. \& Wuest, W. M. Quaternary ammonium compounds: an antimicrobial mainstay and platform for innovation to address bacterial resistance. ACS Infect. Dis. 1, 288-303 (2015).

12 Palomo, C., Oiarbide, M. \& López, R. Asymmetric organocatalysis by chiral Bronsted bases: implications and applications. Chem. Soc. Rev. 38, 632-653 (2009).

13 Lv, J., Qian, Y., Liu, T. \& Wang, Y. Synthesis and evaluation of amphiphilic cationic quinine-derived for antibacterial activity against methicillin-resistance Staphylococcus aureus. Bioorg. Med. Chem. Lett. 17, 4102-4106 (2007).

14 Coates, W. J. et al. The antimicrobial activity of Q-7,0 appeared in a patent. Preparation of piperidinylalkylquinolines as antibacterials. WO 9937635 (1999)

15 Shibagaki, M. et al. The selectivity in $\mathrm{N}$-alkylation of nicotine. Heterocycles 19 , 1641-1645 (1982).

16 Baidya, M., Horn, M., Zipse, H. \& Mayr, H. Organocatalytic activity of cinchona alkaloids: which nitrogren is more nucleophilic? J. Org. Chem. 74, 7157-7164 (2009).

17 Crooks, P. A., Dwoshin, L., Xu, R. \& Ayers, J. Chain-modified pyridine-N substituted nicotine compounds for use in the treatment of CNS pathologies. US Pat. Appl. Publ. 20030225142 (2003).

18 Crooks, P. A. et al. Development of subtype-selective ligands as antagonists at nicotinic receptors mediating nicotine-evoked dopamine release. Bioorg. Med. Chem. Lett. 14 1869-1874 (2004)

19 Singh, P. \& Arora, G. Organic synthesis under PTC: part 6-preparation and decomposition of chiral phase transfer catalysts derived from quinine. Indian J. Chem. Sect. B 25B, 1034-1037 (1986).

20 Gavrilov, K. N., Mikhel, I. S., Lechkin, D. V. \& Timofeeva, G. I. Quinine-based dioxaphospholane with N-decylquinuclidine fragment. Phosphorus Sulfur Silicon Relat. Elem. 108, 285-287 (1996).

Supplementary Information accompanies the paper on The Journal of Antibiotics website (http://www.nature.com/ja) 